Sharif University of Technology
Scientia Iranica
Transactions E: Industrial Engineering
wCIENTIA

\title{
A bi-objective mathematical model for dynamic cell formation problem considering learning effect, human issues, and worker assignment
}

\author{
M. Rabbani*, H. Habibnejad-Ledari, H. Rafiei and A. Farshbaf-Geranmayeh \\ School of Industrial Engineering, College of Engineering, University of Tehran, Tehran, Iran.
}

Received 3 March 2015; received in revised form 14 August 2015; accepted 21 October 2015

KEYWORDS
Dynamic cell
formation;
Human issues;
Linear programming;
Genetic algorithm;
Central composite
design.

\section{Introduction}

Group Technology (GT) is a manufacturing approach that has positive impacts on batch-type production. Cellular Manufacturing System (CMS) is one of the aspects of GT which corresponds to the layout of manufacturing firms that can be used to enhance both flexibility and efficiency of the manufacturing system in today's global competitive environment. Aryanezhad et al. [1] and Rafiei and Ghodsi [2] stated that the

\footnotetext{
*. Corresponding author. Tel.: +982188021067;

Fax: +982188350642

E-mail addresses: mrabani@ut.ac.ir (M. Rabbani);

h_habibnejad@ut.ac.ir (H. Habibnejad-Ledari);

hrafiei@ut.ac.ir (H. Rafiei); afarshbaf@ut.ac.ir (A.

Farshbaf-Geranmayeh)
}

most outstanding benefits of CMS can be summarized as the reduction in lead time, setup time, and lot size. Also, Work-In-Process (WIP) and finished goods inventories as well as the throughput times are reduced, and working flexibility are improved. Designing a CMS consists of the following steps: first, part families are formed according to their processing requirements or geometric design; second, the machines are grouped into manufacturing cells; and third, part families are assigned to the cells [3]. The design of CMSs is called Cell Formation $(\mathrm{CF})$. CF is a part of the CMS that attempts to group machines and part families into specified manufacturing cells. CF is one of the first and most important steps in designing CMSs. Owing to high production variety, short product life cycle, volatile demand, and short delivery time, CMSs are 
performed under dynamic environments [4]. In order to reach an optimal solution under this condition, changes, such as machine modification, should be taken into account.

Human issues should be considered in cellular manufacturing, because failing to take into account this factor can significantly reduce the benefits of cell manufacturing [4]. Bidanda et al. [5] stated that important human issues include worker assignment strategies, training, skill identification, reward/penalty system, communication, worker roles, teamwork, and conflict management. This study presents a biobjective model for the $\mathrm{CF}$ problem which considers learning effect, human issues, and some aspects of motivation in the first objective function. The costs related to human issue consist of salary cost, hiring cost, firing cost, and worker assignment cost. Aspects of motivation such as reward/penalty policy are also taken into consideration. In addition, relevant costs of Dynamic Cell Formation Problem (DCFP) such as operational cost, inventory cost, and outsourcing cost are taken into account concurrently. Second objective function attempted to maximize the labor utilization. The problem being NP-hard, a Linear Programming embedded Genetic Algorithm (LP-GA) is employed, and its parameters are tuned by means of CCD method to solve the model. Also, the obtained results are compared with other approaches.

The remainder of the paper is organized as follows. Section 2 presents the related literature review. Sections 3 and 4 present the model in details. In Section 5, the solution based on the methodology adopted is explained. In Section 6, some numerical examples are given to validate the model. Finally, the conclusion and directions for future research are presented in Section 7.

\section{Literature review}

Nowadays, manufacturing systems have become very important to the global business. A number of factors such as dynamic cell reconfiguration, sequence of operations, alternate part routings, operation time and cost, cost subcontracting, etc. are typically considered in manufacturing CF [6]. Paydar et al. [7] investigated $\mathrm{CF}$ and supply chain simultaneously. They presented a mixed integer linear programming and used a robust optimisation model to solve the proposed model. JabalAmeli and Moshref-Javadi [8] proposed a mathematical model for CF and layout design problems while considering factors such as intra-cell and inter-cell layouts, part demands, operations sequence, etc. Saeidi et al. [9] developed a multi-objective mathematical programming model while considering production volume, machine redundancy, processing time, and sequence of operations to design a CMS and used a GA to solve the proposed model. Bootaki et al. [10] presented a bi-objective model for cube CF. The first part of the model sought to minimize the inter-cell movements, and the second part attempted to maximize a part quality index. Paydar and Saidi-Mehrabad [11] presented a linear programming model in an attempt to maximize the grouping efficacy and developed a hybrid GA and Variable Neighborhood Search (VNS) to validate the model. Solimanpur et al. [12] took into account a number of intercellular movements and the number of voids simultaneously in a CF problem. Lian et al. [13] proposed a bi-objective model to minimize workload imbalance among manufacturing cells and applied a GA to solve it.

Rezazadeh et al. [14] proposed a new model that attempted to determine the optimal number of virtual cells and minimize the different costs such as production, material handling, subcontracting, etc. Kashan et al. [15] studied manufacturing CF problem that deals with grouping parts into families and machines into cells, with the aim of maximizing grouping efficacy. Saxena and Jain [16] dealt with Dynamic CF Problem (DCFP) and presented a mixed integer nonlinear programming with the objective of minimizing costs associated with machine operation, machine breakdown, production planning-related, etc. Bajestani et al. [17] proposed a multi-objective DCFP in an attempt to minimize the total cell load variation and the sum of the miscellaneous costs simultaneously. Shiyas and Pillai [18] developed an algorithm for the design of manufacturing cells and part families with the aim of maximizing grouping efficacy. Wang et al. [19] considered DCFP with three conflicting objectives: the utilization rate of machine capacity, the total number of inter cell moves, and the machine relocation costs.

There are few studies on human issues in cellular manufacturing for several reasons, such as the difficulty in the quantification of these issues. Failing to take into account human aspect of cellular manufacturing can considerably decrease the benefits of this mode. Quantitative studies have demonstrated that laborrelated issues have a critical impact on attaining optimal system performance in a CM [5]. Aryanezhad et al. [1] considered worker assignment and DCF simultaneously. They addressed machine flexibility, part routing, and multi skill workers along with human cost issues related to hiring, firing, training, and salary. Rafiei et al. [4] presented a mathematical model that considered DCFP and worker assignment problem simultaneously as well as motivation, learning effect, and reward. They also incorporated machinebased and human-based costs in their model. Norman et al. [20] presented a model involving human skills, training, worker assignment, and output quality with the objective of maximizing organization effectiveness. 
Ghotboddini et al. [21] studied dynamic CMS and presented a model considering lean production. They attempted to minimize the reassignment cost of human resource, overtime cost of equipment, and labors; attempt was also made to maximize utilization rate of human resource. Rafiei and Ghodsi [2] investigated DCFP by a bi-objective mathematical formulation and attempted to minimize machine-based costs and also maximize labor utilization. They developed a hybrid ant colony optimization-GA approach to solve the model.

A list of the important features in CFP is given in Table 1. Also, Table 2 provides a summary of the researches reported on CFP in the literature.

In comparison with Aryanezhad et al. [1], Rafiei and Ghodsi [2], and Rafiei et al. [4], we defined a policy

Table 1. List of important features in CFP.

\begin{tabular}{cl}
\hline 1 & Material handling cost \\
2 & Machine investment cost \\
3 & Processing time/cost \\
4 & Production volume/demand \\
5 & Cell size limit \\
6 & Outsourcing \\
7 & Overtime \\
8 & Inventory \\
9 & Worker assignment \\
10 & Reward/penalty policy \\
11 & Labor utilization \\
12 & Environment type \\
\hline
\end{tabular}

for reward and penalty costs based on labor utilization and considered labor utilization levels for reward and penalty costs into the proposed model. However, a policy for reward and penalty was not considered in those two papers, and Rafiei et al. [4] took into account reward cost only as a part of objective function. Also, some relevant costs of DCFP, such as inventory and outsourcing, were taken into account in our proposed model, and we addressed labor utilization as the second objective function. Compared to Paydar et al. [7], Saxena and Jain [16], Defersha and Chen [22], and Arikan and Güngör [27], we considered human issues, namely, worker assignment, reward/penalty policy, and labor utilization. Also, we considered outsourcing, overtime, and inventory costs simultaneously.

\section{Proposed model}

In this section, a bi-objective mathematical model is presented in which the first objective is to minimize the costs of DCFP associated with machine procurement, inter-cell movement, machine relocation, machine variable, overtime, inventory, outsourcing, as well as human-related costs including firing, hiring, salary, reward/penalty policy, and worker assignment costs. The second objective function aims to maximize labor utilization. In this model, a CMS is conceived to comprise a number of machines for processing different parts. Learning curve is considered in the model to improve benefits and organizational productivity in reward systems [4]. Newly hired labors are less efficient than the experienced ones, but they can improve their productivity by repeating their tasks $[28,29]$.

Table 2. Overview of the literature on CFP.

\begin{tabular}{|c|c|c|c|c|c|c|c|c|c|c|c|c|}
\hline \multirow{2}{*}{ Paper } & \multicolumn{12}{|c|}{ Feature } \\
\hline & 1 & 2 & 3 & 4 & 5 & 6 & 7 & 8 & 9 & 10 & 11 & $12^{*}$ \\
\hline Aryanezhad et al. [1] & $\mathrm{x}$ & $\mathrm{x}$ & $\mathrm{x}$ & $\mathrm{x}$ & $\mathrm{x}$ & & & & $\mathrm{x}$ & & & 1 \\
\hline Rafiei and Ghodsi [2] & $\mathrm{x}$ & $\mathrm{x}$ & $\mathrm{x}$ & $\mathrm{x}$ & $\mathrm{x}$ & & $\mathrm{x}$ & & & & $\mathrm{x}$ & 1 \\
\hline Rafiei et al. [4] & $\mathrm{x}$ & $\mathrm{x}$ & $\mathrm{x}$ & $\mathrm{x}$ & $\mathrm{x}$ & & & & $\mathrm{x}$ & & & 1 \\
\hline Paydar et al. [7] & $\mathrm{x}$ & $\mathrm{x}$ & $\mathrm{x}$ & $\mathrm{x}$ & $\mathrm{x}$ & & & $\mathrm{x}$ & & & & 2 \\
\hline Saeidi et al. [9] & & $\mathrm{x}$ & $\mathrm{x}$ & $\mathrm{x}$ & $\mathrm{x}$ & & & & & & & 2 \\
\hline Saxena and Jain [16] & $\mathrm{x}$ & $\mathrm{x}$ & $\mathrm{x}$ & $\mathrm{x}$ & $\mathrm{x}$ & $\mathrm{x}$ & & $\mathrm{x}$ & & & & 1 \\
\hline Wang et al. [19] & $\mathrm{x}$ & & $\mathrm{x}$ & $\mathrm{x}$ & $\mathrm{x}$ & & & & & & & 1 \\
\hline Defersha and Chen [22] & $\mathrm{x}$ & $\mathrm{x}$ & $\mathrm{x}$ & $\mathrm{x}$ & $\mathrm{x}$ & $\mathrm{x}$ & & $\mathrm{x}$ & & & & 1 \\
\hline Cao et al. [23] & $\mathrm{x}$ & $\mathrm{x}$ & $\mathrm{x}$ & $\mathrm{x}$ & & & & & & & & 1 \\
\hline Egilmez et al. [24] & & & & $\mathrm{x}$ & $\mathrm{x}$ & & & & & & & 2 \\
\hline Sudhakara Pandian and Mahapatra [25] & $\mathrm{x}$ & & & & & & & & & & & 1 \\
\hline Chung et al. [26] & $\mathrm{x}$ & & $\mathrm{x}$ & $\mathrm{x}$ & $\mathrm{x}$ & & & & & & & 1 \\
\hline Arikan and Güngör [27] & $\mathrm{x}$ & $\mathrm{x}$ & $\mathrm{x}$ & $\mathrm{x}$ & $\mathrm{x}$ & $\mathrm{x}$ & & & & & & 2 \\
\hline This paper & $\mathrm{x}$ & $\mathrm{x}$ & $\mathrm{x}$ & $\mathrm{x}$ & $\mathrm{x}$ & $\mathrm{x}$ & $\mathrm{x}$ & $\mathrm{x}$ & $\mathrm{x}$ & $\mathrm{x}$ & $\mathrm{x}$ & 1 \\
\hline
\end{tabular}

* Note. 1: Deterministic; 2: Uncertain. 
According to the learning curve, the time of an action will be equal to $t_{0} i^{b}$ after some iterations, where $t_{0}$ is the initial time of the job activity, $i$ is the number of iterations, and $b$ is a negative coefficient $[25,26]$.

\subsection{Mathematical model}

\section{Assumptions}

- Demand for each part type, time capacity of each machine type, and processing time for all operations of a part type in each period are known and deterministic;

- All machines of type $m$ can process all part types, $p$

- Each machine type $m$ can perform one or more operations, called machine flexibility;

- Each operation can be performed on one or more machine types with different times, called routing flexibility [1];

- The machines purchasing costs are known and they are purchased with a certain limit;

- Machines are grouped into relatively independent cells with minimum inter-cell movement of the parts;

- Parts are moved between cells in batches (regardless of the distance traveled);

- The maximum number of used cells, bounds, and quantity of machines in each cell need to be specified in advance, and maximum number of cells remains constant over time;

- Each machine needs just one labor;

- Relocation cost of each machine between periods is known;

- In order to process a certain operation, the related machine and labor must be available at the same time [1];

- Backorders are not allowed;

- Workload of the cells should be balanced [16];

- Inventory is equal to zero in the beginning and at the end of the planning horizon;

- Learning curve is considered in the model to increase the benefits and organizational productivity of the systems.

\section{Indices}

c Manufacturing cell $(c=1, \cdots, C)$;

$m \quad$ Machine type $(m=1, \cdots, M)$;

$p \quad$ Part type $(p=1, \cdots, P)$;

$t \quad$ Time period $(t=1, \cdots, T)$;

$j \quad$ Operations belonging to part $p\left(j=1, \cdots, O_{p}\right)$;

$t_{0} \quad$ Time period labors hired $\left(t_{0}=\right.$ $1, \cdots, T)$.

\section{Parameters}

C Number of cells;

$M \quad$ Number of machines;

$P \quad$ Number of part types;

$T \quad$ Number of periods;

$O_{p} \quad$ Number of operations for part type $p$;

$D_{p t} \quad$ Demand for part type $p$ in time period $t$

$B_{p}^{\text {inter }} \quad$ Batch size for inter-cell movements of part type $p$;

$\gamma_{p}^{\text {inter }} \quad$ Inter-cell movement cost per batch of part type $p$;

$\mu_{m} \quad$ Purchase cost of machine type $m$;

$\psi_{m} \quad$ Marginal revenue from selling machine type $m$;

$\lambda_{m} \quad$ Fixed cost of machine type $m$ in each time period;

$C_{m} \quad$ Variable cost of machine type $m$ for each unit time in regular time intervals;

$\theta_{m t} \quad$ Variable cost of processing on machine type $m$ per hour in overtime in time period $t$;

$\delta_{m}^{+} \quad$ Relocation cost of installing one machine of type $m$;

$\delta_{m}^{-} \quad$ Relocation cost of removing one machine of type $m$;

$I C_{p t} \quad$ Inventory cost of per part type $p$ in time period $t$;

$O C_{p t} \quad$ Outsourcing cost of part type $p$ in time period $t$;

$S_{c t} \quad$ Salary cost of each labor in cell $c$ in time period $t$;

$h_{c t} \quad$ Hiring cost of each labor used in cell $c$ in time period $t$;

$f_{c t} \quad$ Firing cost of each labor fired from cell $c$ in time period $t$;

$\phi_{c t}^{r} \quad$ Reward cost for labors in cell $c$ in time period $t$;

$\phi_{c t}^{p} \quad$ The value earned from each labor penalty in cell $c$ in time period $t$;

$T_{m t} \quad$ Time capacity of machine type $m$ in time period $t$ at regular time intervals;

$T_{m t}^{\prime} \quad$ Time capacity of machine type $m$ in time period $t$ in overtime;

Available working time for each worker in hours per time period;

$L B \quad$ Lower bound of the cell size;

$U B \quad$ Upper bound of the cell size;

$t_{j p m} \quad$ Processing time required to perform operation $j$ of part type $p$ on machine type $m$; 
$t_{j p m}^{\prime} \quad$ Manual workload time required to perform operation $j$ of part type $p$ on machine type $m$;

$b \quad$ Learning index;

$q \quad$ Balancing factor of inter-cell workload, $(0 \leq q \leq 1)$;

$R \quad$ A big number;

$A W \quad$ Level of labor utilization which deserves reward;

$P U \quad$ Level of labor utilization which deserves penalty.

\section{Decision variables}

$N_{m c t} \quad$ Number of machines type $m$ allocated to cell $c$ in time period $t$;

$X_{\text {jpmct }} \quad$ Number of parts type $p$ processed by operation $j$ on machine type $m$ in cell $c$ in time period $t$;

$I_{m t}^{+} \quad$ Number of machines type $m$ purchased in period $t$;

$I_{m t}^{-} \quad$ Number of machines type $m$ sold in period $t$;

$K_{m c t}^{+} \quad$ Number of machines type $m$ added in cell $c$ in period $t$;

$K_{m c t}^{-} \quad$ Number of machines type $m$ removed in cell $c$ in period $t$;

$X_{p t} \quad$ Number of parts type $p$ processed in period $t$;

$Q_{p t} \quad$ Number of part inventory of type $p$ kept in period $t$ and carried over to period $t+1$;

$O_{p t} \quad$ Number of parts type $p$ to be subcontracted in period $t$;

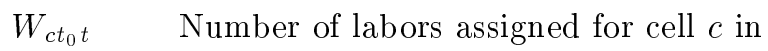
period $t$ hired in period $t_{0}$;

$W_{c t} \quad$ Number of labors assigned for cell $c$ in period $t$;

$H_{c t} \quad$ Number of labors hired for cell $c$ in period $t$;

$F_{c t} \quad$ Number of labors fired for cell $c$ in period $t$;

$L U_{c t} \quad$ Labor utilization in cell $c$ in period $t$;

$Z_{j p c t} \quad 1$, if operation $j$ of type $p$ is done in cell $c$ in period $t ; 0$ otherwise;

$\vartheta_{p t} \quad 1$, if part $p$ is set up for production in period $t ; 0$ otherwise;

$T_{m c t}^{\prime} \quad$ Amount of extra time required by machine $m$ located in cell $c$ in period $t$;

$y_{c t}^{r} \quad 1$, if LUct is more than $A W ; 0$ otherwise;

$y_{c t}^{p} \quad 1$, if $L U_{c t}$ is less than $P U ; 0$ otherwise.

\section{Objective function}

$$
\min z_{1}=\sum_{t=1}^{T} \sum_{c=1}^{C} \sum_{m=1}^{M} N_{m c t} \lambda_{m}
$$

$+\sum_{t=1}^{T} \sum_{c=1}^{C} \sum_{m=1}^{M} \sum_{p=1}^{P} \sum_{j=1}^{O_{p}} C_{m} X_{j p m c t} t_{j p m}$

(2)

$+\sum_{t=1}^{T} \sum_{m=1}^{M} I_{m t}^{+} \mu_{m}-\sum_{t=1}^{T} \sum_{m=1}^{M} I_{m t}^{-} \psi_{m}$

$+\sum_{t=1}^{T} \sum_{c=1}^{C} \sum_{m=1}^{M} \delta_{m}^{+} K_{m c t}^{+}$

$+\sum_{t=1}^{T} \sum_{c=1}^{C} \sum_{m=1}^{M} \delta_{m}^{-} K_{m c t}^{-}$

(6)

$+\frac{1}{2} \sum_{t=1}^{T} \sum_{c=1}^{C} \sum_{p=1}^{P} \sum_{j=1}^{O_{p}-1} \frac{\gamma_{p}^{\text {inter }}}{B_{p}^{\text {inter }}}$

$X_{p t}\left(\left|Z_{(j+1) p c t}-Z_{j p c t}\right|\right)$

(7)

$+\sum_{t=1}^{T} \sum_{p=1}^{P} I C_{p t} Q_{p t}+\sum_{t=1}^{T} \sum_{p=1}^{P} O C_{p t} O_{p t}$

(8)

$+\sum_{t=1}^{T} \sum_{c=1}^{C} \sum_{m=1}^{M} T_{m c t}^{\prime} \theta_{m t}$

$+\sum_{t=1}^{T} \sum_{c=1}^{C} \sum_{t_{0}=1}^{T} S_{c t} W_{c t_{0} t}$

(11)

$+\sum_{t=1}^{T} \sum_{c=1}^{C} h_{c t} H_{c t}+\sum_{t=1}^{T} \sum_{c=1}^{C} f_{c t} F_{c t}$

$+\sum_{t=1}^{T} \sum_{c=1}^{C} \sum_{t_{0}=1}^{T} \phi_{c t}^{r} W_{c t_{0} t} y_{c t}^{r}$

$-\sum_{t=1}^{T} \sum_{c=1}^{C} \sum_{t_{0}=1}^{T} \phi_{c t}^{p} W_{c t_{0} t} y_{c t}^{p}$ 


$$
\max z_{2}=\sum_{t=1}^{T} \sum_{c=1}^{C} L U_{c t}
$$

Subject to:

$$
\begin{array}{lc}
\sum_{c=1}^{C} Z_{j p c t}=\vartheta_{p t} & \forall j, p, t, \\
X_{j p m c t} \leq R . \vartheta_{p t} & \forall j, p, m, c, t, \\
\sum_{p=1}^{P} \sum_{j=1}^{O_{p}} X_{j p m c t} t_{j p m} Z_{j p c t} \leq T_{m t} N_{m c t}+T_{m c t}^{\prime}
\end{array}
$$$$
\forall m, c, t,
$$

$$
\begin{array}{ll}
\sum_{c=1}^{C} T_{m c t}^{\prime} \leq T_{m t}^{\prime} & \forall m, t \\
w_{c t}=w_{c(t-1)}+H_{c t}-F_{c t} & \forall c, t,
\end{array}
$$

where:

$$
\begin{gathered}
w_{c t}=\sum_{t_{0}=1}^{T} W_{c t_{0} t} \quad \forall c, t, \\
A \sum_{c=1}^{C}\left[\left(t-t_{0}\right)^{b} W_{c t_{0} t}+H_{c t}-F_{c t}\right] \\
\geq \sum_{c=1}^{C} \sum_{m=1}^{M} T_{m t} N_{m c t}+\sum_{c=1}^{C} \sum_{m=1}^{M} T_{m c t}^{\prime} \\
\forall t, t_{0}<t, \\
\sum_{c=1}^{C} N_{m c t}-\sum_{c=1}^{C} N_{m c(t-1)}=I_{m t}^{+}-I_{m t}^{-} \quad \forall m, t, \\
N_{m c(t-1)}+K_{m c t}^{+}-K_{m c t}^{-}=N_{m c t}, \quad \forall m, c, t, \\
\sum_{m=1}^{M} N_{m c t} \geq L B \quad \forall c, t, \\
\sum_{m=1}^{M} N_{m c t} \leq U B \quad \forall c, t, \\
Q_{p(t-1)}+O_{p t}+X_{p t}-Q_{p t} \geq D_{p t} \quad \forall p, t,
\end{gathered}
$$

where:

$$
\begin{aligned}
X_{p t} & =\sum_{c=1}^{C} \sum_{m=1}^{M} X_{j p m c t} \quad \forall j, p, t, \\
\sum_{m=1}^{M} \sum_{p=1}^{P} \sum_{j=1}^{O_{p}} X_{j p m c t} t_{j p m} Z_{j p c t} & \\
& \geq q\left[\frac{1}{C} \sum_{c=1}^{C} \sum_{m=1}^{M} \sum_{p=1}^{P} \sum_{j=1}^{O_{p}} X_{j p m c t} t_{j p m} Z_{j p c t}\right]
\end{aligned}
$$$$
\forall c, t,
$$

$\frac{\sum_{m=1}^{M} \sum_{p=1}^{P} \sum_{j=1}^{O_{p}} X_{j p m c t} t_{j p m}^{\prime} Z_{j p c t}}{W_{c t} A} \geq L U_{c t}$

$$
\begin{array}{cc}
\forall c, t, & \\
L U_{c t}-A W \leq R y_{c t}^{r} & \forall c, t, \\
L U_{c t}-P U \leq R\left(1-y_{c t}^{p}\right) & \forall c, t, \\
Z_{j p m c t}, y_{c t}^{r}, y_{c t}^{p}, \vartheta_{p t}, a_{m c t} \in\{0,1\}, L U_{c t} & \\
\in[0,1], X_{j p m c t}, X_{p t}, Q_{p t}, O_{p t}, T_{m c t}^{\prime} \geq 0, \\
\forall j, p, m, c, t, \\
N_{m c t}, I_{m t}^{+}, I_{m t}^{-}, K_{m c t}^{+}, K_{m c t}^{-}, W_{c t_{0} t}, W_{c t}, H_{c t}, F_{c t} \\
\geq 0 \text { and integer } & \forall m, c, t, t_{0} .
\end{array}
$$

The first objective function consists of different cost terms as follows: Term (1) represents fixed cost of machines and depends on the number of machines. Term (2) indicates machine variable cost. Term (3) shows machine procurement cost. Term (4) denotes machine selling income. Terms (5) and (6) represent machine relocation cost which consists of installing and removing costs. Term (7) shows inter-cell movement cost. Term (8) represents part holding cost. Term (9) indicates part outsourcing cost. Term (10) represents overtime cost. Terms (11)-(13) show labors salary, hiring, and firing costs. Terms (14) and (15) refer to reward and penalty costs. Lastly, labor utilization is maximized by the second objective function (i.e., Term (16)).

Eq. (17) and Constraint (18) guarantee that parts are processed if they are planned to produce. Constraint (19) ensure time capacities of planning periods. Constraint (20) limit the utilized extra time. Eq. (21) represent the labor balancing equation. Constraint (22) satisfy the total demand in each period. Eqs. (23) and (24) balance machine quantities between any successive planning periods. Constraints (25) and (26) ensure lower and upper bounds of the number 
of machines in cells. Constraint (27) show that demand of part type $p$ in each time period $t$ is satisfied through internal part production, part outsourcing, and/or part inventory carried over from the previous period $t-1$. Constraint (28) enforce workload balance among cells. Labor utilization is modeled by inequality Constraint (29). Constraints (30) and (31) indicate the applied reward or penalty policy, which depends on labor utilization value. Finally, types and ranges of all variables are presented in Constraints (32) and (33).

The model is then converted into a single objective model using the Weighted Sum Method (WSM). Term (16) is incorporated into the first objective function with a negative coefficient as follows:

$$
-\sum_{t=1}^{T} \sum_{c=1}^{C} L U_{c t}
$$

In order to prevent scaling problem, normalization of the objective functions should be taken into account. It is assumed that $F_{1}$ refers to the first objective function and $F_{2}$ is the second objective function. $y_{1}^{I}$ and $y_{2}^{I}$ are ideal solutions of the first and second objective functions, respectively. $y_{1}^{N}$ and $y_{2}^{N}$ are nadir solutions of the first and second objective functions, respectively. Also, $W_{1}$ and $W_{2}$ are weights of the first and second objective functions, respectively. The integrated objective function is given as follows:

$$
F=W_{1} \times \frac{F_{1}-y_{1}^{I}}{y_{1}^{N}-y_{1}^{I}}+W_{2} \times \frac{F_{2}-y_{2}^{I}}{y_{2}^{I}-y_{2}^{N}} .
$$

\subsection{Model simplification}

The presented model is nonlinear due to the 7 th, 14 th, and 15th terms of the objective function, the time capacity constraints (Eq. (19)), the workload balancing constraints (Eq. (28)), and labor utilization constraints (Eq. (29)). The nonlinear term $X_{p t}\left|Z_{(j+1) p c t}-Z_{j p c t}\right|$ in the 7th term can be linearized by Eqs. (36)-(40) and is then replaced by variable $\eta_{j p m c t}$. The nonlinear term $W_{c t_{0} t} . y_{c t}^{r}$ in the 14 th term and $W_{c t_{0} t} \cdot y_{c t}^{p}$ in the 15 th term can be linearized through Eqs. (41)-(43) and (44)-(46) and are replaced by variables $E_{c t_{0} t}$ and $E E_{c t_{0} t}$, respectively. The nonlinear term $X_{j p m c t} . Z_{j p c t}$ in Eqs. (19), (28), and (29) are linearized by Eqs. (47)(49) and is replaced by the variable $G_{j p m c t}$.

$$
\begin{array}{ll}
Z_{(j-1) p c t}-Z_{j p c t} \leq \xi_{j p c t} & \forall j, p, c, t, \\
-Z_{(j-1) p c t}+Z_{j p c t} \leq \xi_{j p c t} & \forall j, p, c, t, \\
\eta_{j p m c t} \leq X_{j p m c t} & \forall j, p, m, c, t, \\
\eta_{j p m c t} \leq R \cdot \xi_{j p c t} & \forall j, p, m, c, t, \\
\eta_{j p m c t} \geq X_{j p m c t}-R\left(1-\xi_{j p c t}\right) & \forall j, p, m, c, t,
\end{array}
$$

$$
\begin{array}{ll}
E_{c t_{0} t} \leq W_{c t_{0} t} & \forall c, t_{0}, t, \\
E_{c t_{0} t} \leq R . y_{c t}^{r} & \forall c, t_{0}, t, \\
E_{c t_{0} t} \geq W_{c t_{0} t}-R\left(1-y_{c t}^{r}\right) & \forall c, t_{0}, t, \\
E E_{c t_{0} t} \leq W_{c t_{0} t} & \forall c, t_{0}, t \\
E E_{c t_{0} t} \leq R . y_{c t}^{p} & \forall c, t_{0}, t, \\
E E_{c t_{0} t} \geq W_{c t_{0} t}-R\left(1-y_{c t}^{p}\right) & \forall c, t_{0}, t, \\
G_{j p m c t} \leq X_{j p m c t} & \forall j, p, m, c, t, \\
G_{j p m c t} \leq R . Z_{j p c t} & \forall j, p, m, c, t, \\
G_{j p m c t} \geq X_{j p m c t}-R\left(1-Z_{j p c t}\right) & \forall j, p, m, c, t, \\
\xi_{j p c t} \in\{0,1\}, \eta_{j p m c t}, E_{c t_{0} t}, E E_{c t_{0} t}, G\left(G_{j p m c t} \geq 0\right. \\
\forall j, p, m, c, t .
\end{array}
$$

\section{Solution methodology}

In this section, the hybrid LP-GA approach as the applied methodology is discussed in detail.

\subsection{LP-GA approach}

Due to the NP-hard nature of the problem, a LPGA approach is applied to solve it. GA is one of the optimization approaches based on the mechanism of natural selection. This algorithm attempts to mimic natural processes in order to create optimization procedures. GA has gained increasing popularity for solving different optimization problems and has been used in different areas such as engineering, manufacturing, etc. [30]. A GA starts with a feasible solution and in each iteration, the current solution is replaced with a new one [31]. To reproduce and generate offsprings, GA uses genetic operators which generally consist of selection, crossover, and mutation. Also, GA utilizes a fitness function to measure the quality of each encoded solution. Some of the typical unique features of GA that distinguish it from other algorithms include population-based search, searching and evaluating a large number of feasible points in the solution space, implicit parallelism, flexibility of hybridizing with other domain-dependent heuristics, and taking advantage of the probabilistic theory for selection to direct their search [30]. Based on the foregoing discussion, GA can decrease the possibility of being trapped in a local optima. In the developed algorithm, the values of the integer variables are obtained by decoding the solution representation. Also, using an optimization software, a linear programming is solved to find the corresponding values of the continuous variables and 
those of the objective function. The advantage of LPGA approach is that when the LP is solved, values that optimally correspond to the integer solution can be yielded simply. Also, while it appears to be hard to satisfy several constraints with continuous variables through only GA, the LP satisfies them easily [22].

\subsection{Chromosome representation}

The first step in GA is designing chromosome characteristics to devise a suitable representation scheme and maintaining the feasibility of the generated chromosomes. Each chromosome is represented by a sequence of genes which can be a set of real, binary or integer numbers, symbols, and matrices. Two approaches are used to represent the chromosome: direct and indirect encodings. In a direct encoding, a chromosome totally represents a solution, while in an indirect encoding, a chromosome involves data which are used to achieve a solution [31]. In this paper, both direct and indirect coding schemes are used to represent the chromosomes. In the proposed representation, four types of chromosomes (i.e., $N, W, \vartheta$, and $L$ ) are considered. The first two chromosomes which are related to decision variables, $N_{m c t}$ and $W_{c t_{0} t}$, are $m \times c \times t$ and $c \times t_{0} \times t$ matrices, respectively. The last two chromosomes which relate to decision variables, $\vartheta_{p t}$ and $L_{j p}$, are $p \times t$ and $j \times p$ matrices, respectively. The chromosome $N$ which denotes the number of machines type $m$ installed in cell $c$ during time period $t$ takes a positive integer value. The second chromosome is $W$ which takes a positive integer value. It indicates the number of labors assigned to cell $c$ during time period $t$ which is used in time period $t_{0}$. The chromosome $\vartheta$ is a binary variable that shows whether or not part $p$ has been planned for production in time period $t$. The chromosome $L$ takes a value in $\{1, \cdots, C\}$ and shows the index of the cell in which operation $j$ of part type $p$ is to be processed.

\subsection{Decoding chromosomes}

The values of decision variables $N_{m c t}, W_{c t_{0} t}$, and $\vartheta_{p t}$ are read directly from the chromosome, while the decision variable, $Z_{j p c t}$, is determined using Eq. (51). Based on this equation, the constraint in Eq. (17) can be satisfied.

$$
Z_{j p c t}= \begin{cases}\vartheta_{p t} & \text { if the subscript } c=L_{j p} \\ 0 & \text { otherwise }\end{cases}
$$

Also, decision variables $K_{m c t}^{+}, K_{m c t}^{-}, I_{m t}^{+}, I_{m t}^{-}, H_{c t}$, and $F_{c t}$ can be determined using Eqs. (52)-(57), respectively. These equations satisfy Constraints (21)-(24).

$$
K_{m c t}^{+}= \begin{cases}N_{m c t} & \text { if } t=1 \\ \max \left\{0, N_{m c t}-N_{m c(t-1)}\right\} & \text { if } t>1\end{cases}
$$

$$
\begin{aligned}
& K_{m c t}^{-}= \begin{cases}0 & \text { if } t=1 \\
\max \left\{0, N_{m c(t-1)}-N_{m c t}\right\} & \text { if } t>1\end{cases} \\
& I_{m t}^{+}= \begin{cases}\sum_{c=1}^{C} N_{m c t} & \text { if } t=1 \\
\max \left\{0, \sum_{c=1}^{C} N_{m c t}-\sum_{c=1}^{C} N_{m c(t-1)}\right\} & \text { if } t>1\end{cases} \\
& I_{m t}^{-}= \begin{cases}0 & \text { if } t=1 \\
\max \left\{0, \sum_{c=1}^{C} N_{m c(t-1)}-\sum_{c=1}^{C} N_{m c t}\right\} & \text { if } t>1\end{cases} \\
& H_{c t}=\left\{\begin{array}{l}
\sum_{t_{0}=1}^{T} W_{c t_{0} t} \\
\text { if } t=1, \quad t_{0} \leq t \\
\max \left\{0, \sum_{t_{0}=1}^{T} W_{c t_{0} t}-\sum_{t_{0}=1}^{T} W_{c t_{0}(t-1)}\right\} \\
\text { if } t>1, t_{0} \leq t
\end{array}\right. \\
& F_{c t}=\left\{\begin{array}{l}
0 \\
\text { if } t=1 \\
\max \left\{0, \sum_{t_{0}=1}^{T} W_{c t_{0}(t-1)}-\sum_{t_{0}=1}^{T} W_{c t_{0} t}\right\} \\
\quad \text { if } t>1, \quad t_{0} \leq t
\end{array}\right.
\end{aligned}
$$

\subsection{LP method}

The values of all the integer decision variables are obtained by decoding a chromosome and using the penalty method as explained in the previous sections. The constraints containing only the integer variables are satisfied by decoding the chromosomes except Constraints (25) and (26), which are dealt with by the penalty method. The corresponding continuous values are determined by solving a linear programming. The objective function of this LP involves Terms (2), (7)(10), and (34) subject to the constraints in Eqs. (18)(20), (22), and (27)-(31). First, the integer variables are satisfied by proposed GA, and the model with the corresponding continuous values are solved by branch and bound algorithm using GAMS optimization software.

\subsection{Fitness function}

Fitness function is used to evaluate the candidate solutions in the population and reproduce new chromosomes, called offsprings. In the proposed algorithm, the fitness value of a chromosome is defined as the objective function value (Terms (1)-(15) and (34)) and the penalty term of constraints violation. The factor 
PV is used to scale the penalty term.

Fitness function $=$ model objective function

$$
\begin{aligned}
& +P V \sum_{t=1}^{T} \sum_{c=1}^{C} \max \{0, L B \\
& \left.-\sum_{m=1}^{M} N_{m c t}, \sum_{m=1}^{M} N_{m c t}-U B\right\} .
\end{aligned}
$$

\subsection{Selection}

The Roulette Wheel selection procedure is a fitnessproportional selection in which an individual with higher fitness will be selected with a higher probability [32]. In this procedure, all individuals will have a chance to be selected, but superior individuals will have a higher selection probability.

\subsection{Genetic operators}

Crossover and mutation, as two genetic operators, are used to produce new offsprings from the selected parents. The crossover and mutation used in the proposed model are discussed below.

\subsubsection{Crossover}

Crossover as the main genetic operator combines information from two parents and reproduces two new chromosomes. In this paper, a uniform crossover is applied to produce new chromosomes. In the uniform crossover, the binary chromosome $\alpha$ is randomly generated as large as the main chromosome. For offspring 1, if $\alpha=1$, the gene is taken from parent 1 ; if $\alpha=0$, the gene is taken from parent 2. For offspring 2 , if $\alpha=1$, the gene is taken from parent 2 ; if $\alpha=0$, the gene is taken from parent 1. Eq. (59) shows the proposed crossover:

Offspring $1=\alpha \times$ parent $1+(1-\alpha) \times$ parent 2 ,

Offspring $2=\alpha \times$ parent $2+(1-\alpha) \times$ parent 1 .

The pseudo code of the proposed crossover operator for variable $N_{m c t}$ is shown in Figure 1.

\subsubsection{Mutation}

Mutation operator is used to keep the diversity of the population at a reasonable level with producing random changes in a chromosome. In this paper, a binary mutation is applied to produce new chromosomes. In the binary mutation, first, we determine parameter $\mu$ usually equal to 0.001 or 0.01 . The number of mutations ( $\mathrm{nm}$ ) is then specified by means of the equation represented below (where $N$ denotes the number of genes in the chromosome). Subsequently, genes are selected randomly and mutation operator is applied to the chromosome. Based on the chromosome type, the selected genes can take different values.

$$
n m=[\mu \times N]+1 .
$$

For example, a random value is generated between $[1, C]$, and assigned to the selected gene in chromosome $L$ for $L_{j p}$.

\subsection{Parameters tuning}

The performance of GA strongly relies on its parameters including population size, number of iterations, crossover probabilities, and mutation probabilities. As a single set of GA, the parameters are not guaranteed to obtain a near-optimum solution for the problem. The Central Composite Design (CCD) method is applied to tune GA parameters so as to determine appropriate population size and number of iterations, as well as crossover and mutation probabilities. CCD, also called response surface methodology, extracts the relationship between responses and effective factors [33]. By implementing the CCD, regression coefficients for effective factors are extracted. Then, an optimization software is applied to find the optimum combination of effective factors. Factors and their levels are shown in Table 1.

\section{Computational results}

To demonstrate the performance of the proposed algorithm and to verify the feasibility of the proposed model, 25 numerical samples are tested. Tables 3 and 4 present data of the numerical examples. In Table 5, the range of parameters used in the model is presented. These parameters are generated uniformly. The LPGA approach has been coded in Matlab 7 and run on a PC core i5, $1.8 \mathrm{GHz}$ speed with $6 \mathrm{~GB}$ of RAM.

In these tests problems, lower and upper bounds are 2 and 6, respectively. Batch size is 40 and the cost of each batch is equal to 30 . Different learning rates have been considered in the literature. Heizer and Render [34] showed that the learning rate could

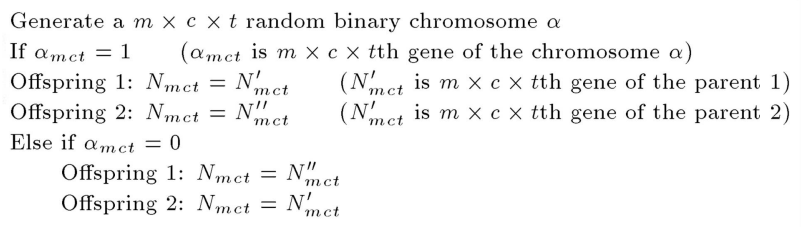

Figure 1. Pseudo code of the proposed crossover. 
Table 3. Designed factors and their levels.

\begin{tabular}{lcc}
\hline \multirow{2}{*}{ Factors } & \multicolumn{2}{c}{ Levels } \\
\cline { 2 - 3 } & Low & High \\
\hline Iteration (maxit) & 150 & 250 \\
Population size (npop) & 100 & 200 \\
Crossover probability $(p c)$ & 0.7 & 0.8 \\
Mutation probability $(p m)$ & 0.3 & 0.4 \\
\hline
\end{tabular}

Table 4. Test problems.

\begin{tabular}{cccccc}
\hline No. & $\boldsymbol{J}$ & $\boldsymbol{P}$ & $\boldsymbol{M}$ & $\boldsymbol{C}$ & $\boldsymbol{T}$ \\
\hline 1 & 3 & 4 & 4 & 2 & 2 \\
2 & 4 & 4 & 4 & 2 & 2 \\
3 & 5 & 5 & 5 & 2 & 2 \\
4 & 6 & 5 & 5 & 2 & 2 \\
5 & 6 & 6 & 5 & 3 & 2 \\
6 & 6 & 6 & 6 & 3 & 3 \\
7 & 7 & 7 & 6 & 3 & 3 \\
8 & 8 & 7 & 7 & 3 & 3 \\
9 & 7 & 8 & 7 & 3 & 3 \\
10 & 8 & 8 & 7 & 3 & 2 \\
11 & 8 & 8 & 8 & 3 & 3 \\
12 & 9 & 8 & 8 & 3 & 3 \\
13 & 9 & 9 & 9 & 3 & 3 \\
14 & 10 & 10 & 10 & 3 & 2 \\
15 & 11 & 11 & 11 & 3 & 3 \\
16 & 12 & 12 & 12 & 3 & 3 \\
17 & 14 & 14 & 12 & 3 & 3 \\
18 & 15 & 15 & 15 & 4 & 3 \\
19 & 17 & 17 & 15 & 4 & 3 \\
20 & 18 & 20 & 16 & 4 & 2 \\
21 & 19 & 19 & 16 & 4 & 2 \\
22 & 19 & 22 & 17 & 4 & 2 \\
23 & 20 & 23 & 18 & 4 & 2 \\
24 & 20 & 25 & 20 & 4 & 2 \\
\hline & 22 & 27 & 20 & 4 & 2 \\
\hline & & & &
\end{tabular}

range between 0.7 and 0.9 for different industries. Also, several studies, such as $[35,36]$, considered the learning rate to be at the interval of [0.7 0.9]. In this paper, this rate is assumed to be 0.85 . It should be mentioned that the learning index $(b)$ is calculated as the logarithm
Table 5. Data of the test problems.

\begin{tabular}{cccc}
\hline Parameter & $\begin{array}{c}\text { Data } \\
\text { range }\end{array}$ & Parameter & $\begin{array}{c}\text { Data } \\
\text { range }\end{array}$ \\
\hline$D_{p t}$ & {$[200300]$} & $t_{j p m}^{\prime}$ & {$\left[\begin{array}{ll}5 & 8\end{array}\right]$} \\
$\theta_{m t}$ & {$\left[\begin{array}{ll}20 & 35\end{array}\right]$} & $\mu_{m}$ & {$\left[\begin{array}{cc}550 & 680\end{array}\right]$} \\
$S_{c t}$ & {$\left[\begin{array}{lll}150 & 180\end{array}\right]$} & $\psi_{m}$ & {$[300500]$} \\
$h_{c t}$ & {$\left[\begin{array}{lll}140 & 170\end{array}\right]$} & $\lambda_{m}$ & {$\left[\begin{array}{ll}5 & 10\end{array}\right]$} \\
$f_{c t}$ & {$\left[\begin{array}{lll}15 & 17\end{array}\right]$} & $C_{m}$ & {$\left[\begin{array}{ll}5 & 10\end{array}\right]$} \\
$T_{m t}$ & {$\left[\begin{array}{lll}700 & 800\end{array}\right]$} & $\delta_{m}^{+}$ & {$[3040]$} \\
$T_{m t}^{\prime}$ & {$\left[\begin{array}{lll}140 & 160\end{array}\right]$} & $\delta_{m}^{-}$ & {$[3040]$} \\
$t_{j p m}$ & {$\left[\begin{array}{ll}3 & 5\end{array}\right]$} & & \\
\hline
\end{tabular}

to base 2 of learning rate (i.e., $b=-0.2$ ). The parameters of $A W, P U$, and $q$ are determined with the coordination of three academic and two industrial experts. Based on their opinions, the value of $A W, P U$, and $q$ are assumed to be $0.8,0.4$, and 0.5 , respectively. The inventory cost is 150 , outsourcing cost is 300 , and the reward and penalty values are 40 and 30 , respectively.

To improve the performance of the proposed approach, effective GA parameters are tuned by CCD. Each parameter takes values in different levels. So, to obtain reasonable computational results, a CCD method is adopted to determine the best levels of the parameters including maxit, npop, pc, and pm. Moreover, regression coefficients are extracted and shown in Table 6. Also, the optimum solutions obtained from GAMS are shown in Table 7 . The values maxit $=150$, $n p o p=200, p c=0.7$, and $p m=0.4$ are selected to improve the performance of proposed algorithm.

The obtained results of the problems are shown in Table 8. In this table, numbers in each cell correspond to the machines and demonstrate the ones that are assigned to the cells. Also, the CPU running time of algorithm is presented in Table 8 . Table 9 shows the results of the 10 test problems applying two methods (GA and an exact method) and shows a comparison of these methods and our proposed GA-TS. In the exact method, the branch and bound algorithm is applied using GAMS optimization software. The following formula is used for computing the gaps:

$$
\begin{aligned}
& \text { Gap } 1=\frac{\text { proposed approach }- \text { exact method }}{\text { proposed approach }} \\
& \text { Gap } 2=\frac{\text { GA }- \text { proposed approach }}{\text { GA }}
\end{aligned}
$$

Table 9 shows the performance of proposed GA-TS algorithm with respect to the GA algorithm and the exact method. Each test problem is solved 15 times and we choose the minimum cost. Table 9 shows 
Table 6. Estimated regression coefficients.

\begin{tabular}{lllrc}
\hline \multicolumn{1}{c}{ Term } & \multicolumn{1}{c}{ Coef. } & \multicolumn{1}{c}{ SE coef. } & $\boldsymbol{T}$ & $\boldsymbol{P}$ \\
\hline Constant & 421576 & 550855 & 0.765 & 0.445 \\
Maxit & 6018 & 1342 & 4.483 & 0.000 \\
Npop & -221 & 1305 & -0.169 & 0.886 \\
Pc & -608078 & 787436 & -0.772 & 0.441 \\
Pm & -3102328 & 1506105 & -2.060 & 0.040 \\
maxit $*$ maxit & 3 & 2 & 1.669 & 0.096 \\
npop $*$ npop & 5 & 2 & 3.171 & 0.002 \\
pc $*$ pc & 871820 & 399475 & 2.182 & 0.030 \\
pm $*$ pm & 3794461 & 1597901 & 2.375 & 0.018 \\
maxit $* n p o p$ & -2 & 2 & -1.066 & 0.287 \\
maxit $*$ pc & -8283 & 1068 & -7.755 & 0.000 \\
maxit $*$ pm & -518 & 2136 & -0.243 & 0.808 \\
npop $*$ pc & 874 & 1068 & 0.819 & 0.414 \\
npop $*$ pm & -6357 & 2136 & -2.976 & 0.003 \\
pc $*$ pm & 1775040 & 1068097 & 1.662 & 0.098 \\
$S=16888$ & $R-S_{q}=55.7 \%$ & $R-S_{q}($ adj $)$ & & \\
\hline
\end{tabular}

Table 7. Optimum values of GA factors obtained from CCD.

\begin{tabular}{cccc}
\hline $\begin{array}{c}\text { Maximum } \\
\text { iteration } \\
(\boldsymbol{m a x i t})\end{array}$ & $\begin{array}{c}\text { Population } \\
\text { size } \\
(\boldsymbol{n} \boldsymbol{p o p})\end{array}$ & $\begin{array}{c}\text { Crossover } \\
\text { probability } \\
(\boldsymbol{p c})\end{array}$ & $\begin{array}{c}\text { Mutation } \\
\text { probability } \\
(\boldsymbol{p m})\end{array}$ \\
\hline 150 & 200 & 0.7 & 0.4 \\
\hline
\end{tabular}

that the proposed approach has acceptable capacity to obtain a good solution in large-sized problems. Also, if the results of the proposed algorithm are compared with those of GA, the proposed algorithm obviously outperforms this algorithm. The values of Gaps 1 and 2 are presented in Table 9 .

\section{Conclusions and directions for future research}

Human-related issues such as problems associated with salary, hiring, firing, and worker assignment are among the most important issues in DCFP, which have been ignored in the literature. In this paper, a new biobjective mathematical model was proposed to deal with dynamic CF and human-related issues. The first objective function was separated into two parts. The first part was related to machine-based costs, such as operational cost, inter-cell movement cost, machine procurement cost, relocation cost, machine variable cost, inventory cost, outsourcing cost, and overtime cost. The second part was related to human-related costs including salary, hiring, firing, and worker assignment costs. In this part, some aspects of motivation, namely reward/penalty policy, were also taken into account. The second objective function considered labor utilization which is a criterion for reward/penalty policy. Since, in the real world, the available time in different conditions is not constant, in order to indicate the real workers time, learning effect was incorporated in the model. The problem was NPhard, and thus a LP-GA approach was employed to solve the model. Also, to improve the performance of the proposed approach, effective GA parameters were tuned by the CCD. Furthermore, to validate the proposed approach, several test problems with different sizes were generated randomly and solved by an exact method, GA, and the proposed approach. Lastly, the results obtained were compared with each other. Computational results show that the proposed approach enjoys the potential to obtain good solution in large-sized problems. Also, it outperforms the GA in most of the test problems.

In order to increase system flexibility, crosstraining is often used. It results in multi-skilled operators and reduces the processing time and the time periods that depend on operator. Considering crosstraining can be a significant contribution to continue the current research directions. Also, Our purpose was to investigate human issues theoretically, and their 
Table 8. Cell configurations of the test problems.

\begin{tabular}{|c|c|c|c|c|c|c|c|c|c|c|c|c|c|}
\hline \multirow{2}{*}{$\begin{array}{l}\text { Test } \\
\text { no. }\end{array}$} & \multirow{2}{*}{$\begin{array}{l}\mathrm{CPU} \\
\text { time } \\
(\mathrm{sec})\end{array}$} & \multicolumn{4}{|c|}{$T=1$} & \multicolumn{4}{|c|}{$T=2$} & \multicolumn{4}{|c|}{$T=3$} \\
\hline & & $C=1$ & $C=2$ & $C=3$ & $C=4$ & $C=1$ & $C=2$ & $C=3$ & $C=4$ & $C=1$ & $C=2$ & $C=3$ & $C=4$ \\
\hline 1 & 52 & 2 & $2,3,4$ & & & 1,2 & 3,4 & & & & & & \\
\hline 2 & 81 & 1,2 & $2,3,4$ & & & 1,2 & 3,4 & & & & & & \\
\hline 3 & 103 & $2,3,5$ & $\begin{array}{l}2,3 \\
4,5\end{array}$ & & & $2,3,5$ & $\begin{array}{c}2,3 \\
4,5\end{array}$ & & & & & & \\
\hline 4 & 139 & $2,3,5$ & $\begin{array}{l}2,3 \\
4,5\end{array}$ & & & $2,3,5$ & $\begin{array}{c}2,3 \\
4,5\end{array}$ & & & & & & \\
\hline 5 & 218 & $2,3,5$ & 2,4 & $\begin{array}{l}1,2, \\
3,5\end{array}$ & & 2,3 & 2,3 & & & & & & \\
\hline 6 & 353 & $2,3,6$ & $2,3,4$ & 2,4 & & 2,3 & 1,4 & 3 & & 6 & 1 & 2 & \\
\hline 7 & 409 & $2,3,6$ & $2,3,4$ & 2,4 & & $2,3,6$ & $2,3,4$ & 2,4 & & 1 & 2 & 2 & \\
\hline 8 & 473 & $2,4,7$ & $2,3,1$ & $2,3,7$ & & $2,4,7$ & 2,3 & $2,3,7$ & & $2,4,7$ & $2,3,1$ & $2,3,7$ & \\
\hline 9 & 458 & $2,4,7$ & 2,3 & $2,3,7$ & & $2,4,7$ & 2,3 & $2,3,7$ & & $2,4,7$ & 2,3 & $2,3,7$ & \\
\hline 10 & 512 & $2,4,7$ & 2,1 & $1,3,7$ & & $2,4,7$ & 2,1 & $1,3,7$ & & $2,4,7$ & 2,1 & $1,3,7$ & \\
\hline 11 & 574 & $2,3,4,7$ & $2,6,7$ & $2,4,7$ & & $2,3,4,7$ & $2,4,7$ & $2,4,7$ & & $2,3,4,7$ & $2,4,7$ & 24,7 & \\
\hline 12 & 632 & $\begin{array}{c}2,3 \\
4,7 \\
\end{array}$ & $2,6,7$ & $2,4,7$ & & $\begin{array}{c}2,3 \\
4,7 \\
\end{array}$ & $2,4,7$ & $2,4,7$ & & $2,3,4,7$ & $2,4,7$ & 24,7 & \\
\hline 13 & 682 & $\begin{array}{c}2,3 \\
4,7 \\
\end{array}$ & $2,6,7$ & $\begin{array}{c}2,4 \\
7,1 \\
\end{array}$ & & $\begin{array}{l}2,3 \\
4,7 \\
\end{array}$ & $2,4,7$ & $\begin{array}{c}2,4 \\
7,1 \\
\end{array}$ & & $\begin{array}{l}2,3 \\
4,7 \\
\end{array}$ & $2,4,7$ & $24,7,1$ & \\
\hline 14 & 619 & $2,4,7$ & 2 & $3,7,9$ & & $2,4,7$ & 2,10 & $3,7,9$ & & & & & \\
\hline 15 & 746 & $1,5,6$ & $3,4,7$ & $1,5,8$ & & $6,9,11$ & $\begin{array}{c}1,3 \\
4,9 \\
\end{array}$ & $2,4,6$ & & $3,4,10$ & 9,11 & $1,8,10$ & \\
\hline 16 & 805 & $\begin{array}{c}1,4, \\
5,6 \\
\end{array}$ & $3,4,7$ & $\begin{array}{l}3,5 \\
8,9 \\
\end{array}$ & & $6,9,11$ & $\begin{array}{c}1,3,5 \\
6,12\end{array}$ & $2,4,6$ & & $4,10,12$ & 11,12 & $\begin{array}{c}1,8 \\
10,12 \\
\end{array}$ & \\
\hline 17 & 974 & $\begin{array}{l}4,5 \\
8,11 \\
\end{array}$ & $3,4,7$ & $\begin{array}{l}6,7 \\
8,12 \\
\end{array}$ & $\begin{array}{l}1,3 \\
6,8 \\
\end{array}$ & $\begin{array}{l}3,7 \\
9,11 \\
\end{array}$ & $1,10,12$ & $\begin{array}{l}4,8 \\
9,11 \\
\end{array}$ & $\begin{array}{l}1,2 \\
8,10 \\
\end{array}$ & $3,6,13$ & $1,4,10$ & 9,14 & $1,6,12$ \\
\hline 18 & 989 & $\begin{array}{l}2,5,8, \\
10,11 \\
\end{array}$ & $3,4,14$ & $\begin{array}{c}6,8, \\
12,14 \\
\end{array}$ & $\begin{array}{l}1,3 \\
6,15 \\
\end{array}$ & $\begin{array}{c}3,7, \\
11,15 \\
\end{array}$ & $12,13,14$ & $\begin{array}{l}4,8, \\
9,11 \\
\end{array}$ & $\begin{array}{c}1,2, \\
10,14 \\
\end{array}$ & $3,6,13$ & $\begin{array}{c}1,3,4 \\
6,10 \\
\end{array}$ & 9,14 & $12,13,15$ \\
\hline 19 & 1071 & $\begin{array}{l}4,5,8, \\
10,11 \\
\end{array}$ & $\begin{array}{l}3,4, \\
7,14 \\
\end{array}$ & $\begin{array}{c}7,8, \\
13,15 \\
\end{array}$ & $\begin{array}{c}1,3,6 \\
8,9 \\
\end{array}$ & $\begin{array}{c}3,7, \\
11,15 \\
\end{array}$ & $12,13,14$ & $\begin{array}{c}4,5,8 \\
9,11 \\
\end{array}$ & $\begin{array}{c}1,2, \\
10,14 \\
\end{array}$ & $3,6,13$ & $\begin{array}{c}1,3,4 \\
6,10,11 \\
\end{array}$ & $8,9,14$ & $12,13,15$ \\
\hline 20 & 1190 & $\begin{array}{c}2,4, \\
10,15 \\
\end{array}$ & $\begin{array}{c}1,8, \\
12,13 \\
\end{array}$ & $\begin{array}{l}6,7 \\
9,10 \\
\end{array}$ & $5,7,13$ & $\begin{array}{c}8,5, \\
11,12 \\
\end{array}$ & $\begin{array}{l}1,3,6, \\
13,10 \\
\end{array}$ & $\begin{array}{l}1,8,9, \\
12,16\end{array}$ & $\begin{array}{l}1,4, \\
8,14 \\
\end{array}$ & & & & \\
\hline 21 & 1173 & $\begin{array}{c}3,4,10 \\
11,15\end{array}$ & $\begin{array}{c}3,8, \\
12,13\end{array}$ & $\begin{array}{c}1,2,5 \\
7,10 \\
\end{array}$ & $5,7,13$ & $\begin{array}{c}8,5,11 \\
12,14\end{array}$ & $\begin{array}{l}1,3,6, \\
13,16\end{array}$ & $\begin{array}{l}1,8,9, \\
12,14\end{array}$ & $\begin{array}{l}1,4, \\
8,10\end{array}$ & & & & \\
\hline 22 & 1261 & $\begin{array}{c}2,3,10, \\
11,13,15 \\
\end{array}$ & $\begin{array}{c}3,8, \\
12,14 \\
\end{array}$ & $\begin{array}{c}2,4,5 \\
7,10 \\
\end{array}$ & $\begin{array}{c}5,7 \\
13,17 \\
\end{array}$ & $\begin{array}{c}5,8,11 \\
12,16\end{array}$ & $\begin{array}{c}1,3,6, \\
12,13,16 \\
\end{array}$ & $\begin{array}{l}1,8,9, \\
12,14 \\
\end{array}$ & $\begin{array}{l}1,4,8 \\
10,17\end{array}$ & & & & \\
\hline 23 & 1275 & $\begin{array}{c}1,3,10, \\
13,15,18\end{array}$ & $\begin{array}{c}3,8,12 \\
14,16\end{array}$ & $\begin{array}{c}2,4,5 \\
7,10 \\
\end{array}$ & $\begin{array}{c}5,7 \\
13,17 \\
\end{array}$ & $\begin{array}{c}5,8,10 \\
11,16,18 \\
\end{array}$ & $\begin{array}{c}1,3,11,12 \\
13,16,18 \\
\end{array}$ & $\begin{array}{l}1,8,9 \\
12,14 \\
\end{array}$ & $\begin{array}{c}1,4,8, \\
11,17,18 \\
\end{array}$ & & & & \\
\hline 24 & 1330 & $\begin{array}{c}1,3,10,13 \\
15,18,20 \\
\end{array}$ & $\begin{array}{c}3,5,8, \\
12,14,16 \\
\end{array}$ & $\begin{array}{c}2,4,5 \\
7,10,19 \\
\end{array}$ & $\begin{array}{c}5,7,13 \\
17,19 \\
\end{array}$ & $\begin{array}{c}5,8,10,11 \\
16,18,20 \\
\end{array}$ & $\begin{array}{c}1,3,11,12 \\
13,16,18 \\
\end{array}$ & $\begin{array}{c}8,9,12, \\
14,19,20 \\
\end{array}$ & $\begin{array}{c}1,4,8, \\
11,17,18 \\
\end{array}$ & & & & \\
\hline 25 & 1358 & $\begin{array}{c}1,3,10,13 \\
15,18,20\end{array}$ & $\begin{array}{l}3,5,8,12, \\
14,10,16\end{array}$ & $\begin{array}{c}2,4,5 \\
7,10,17\end{array}$ & $\begin{array}{c}2,5,7 \\
13,17,19\end{array}$ & $\begin{array}{c}1,5,10,11 \\
16,18,20\end{array}$ & $\begin{array}{c}1,3,11,12 \\
13,16,18\end{array}$ & $\begin{array}{l}4,8,9,12 \\
14,19,20\end{array}$ & $\begin{array}{l}1,4,8,11 \\
15,17,18\end{array}$ & & & & \\
\hline
\end{tabular}


Table 9. Performance of proposed method compared to other approaches.

\begin{tabular}{cccccc}
\hline Test number & Proposed approach & GA & Exact method & Gap 1 (\%) & Gap 2 (\%) \\
\hline 1 & 2309.24 & 2319.85 & 2301.53 & 0.3338 & 0.4576 \\
2 & 2452.05 & 2491.36 & 2425.97 & 1.0637 & 1.5780 \\
3 & 3733.57 & 3779.03 & 3703.27 & 0.8115 & 1.2031 \\
4 & 8790.14 & 9064.5 & 8595.46 & 2.2148 & 3.0268 \\
5 & 9174.11 & 9139.46 & 8893.5 & 3.0587 & -0.3791 \\
6 & 10904.76 & 11318.05 & N/A & - & 3.6516 \\
7 & 18566.35 & 18834.11 & N/A & - & 1.4217 \\
8 & 27717.15 & 27299.01 & N/A & - & -1.5317 \\
9 & 43290.27 & 45433.02 & N/A & - & 4.7163 \\
10 & 71935.41 & 75907.66 & N/A & - & 5.2330 \\
\hline
\end{tabular}

applications could be considered as future research direction for interested researchers.

\section{References}

1. Aryanezhad, M.B., Deljoo, V. and Mirzapour Ale-hashem, S.M.J. "Dynamic cell formation and the worker assignment problem: A new model", Int. J. Adv. Manuf. Tech., 41(3-4), pp. 329-342 (2009).

2. Rafiei, H. and Ghodsi, R. "A bi-objective mathematical model toward dynamic cell formation considering labor utilization", Appl. Math. Model., 37(4), pp. 2308-2316 (2013).

3. Papaioannou, G. and Wilson, J.M. "The evolution of cell formation problem methodologies based on recent studies (1997-2008): Review and directions for future research", Eur. J. Oper. Res., 206(3), pp. 509-521 (2010).

4. Rafiei, H., Rabbani, M. and Koushan, M. "Effect of motivation and learning curve in dynamic cell formation and the worker assignment problem", Int. J. Eng. Sci. Res. Tech., 1(9), pp. 481-497 (2012).

5. Bidanda, B., Ariyawongrat, P., Needy, K.L., Norman, B.A. and Tharmmaphornphilas, W. "Human related issues in manufacturing cell design, implementation, and operation: A review and survey", Comput. Ind. Eng., 48(3), pp. 507-523 (2005).

6. Defersha, F.M. and Chen, M. "Machine cell formation using a mathematical model and a genetic algorithmbased heuristic", Int. J. Prod. Res., 44(12), pp. 24212444 (2006).

7. Paydar, M.M., Saidi-Mehrabad, M. and Teimoury, E. "A robust optimisation model for generalized cell formation problem considering machine layout and supplier selection", Int. J. Comput. Integr. Manuf., 27(8), pp. 772-786 (2014).

8. Jabal-Ameli, M.S. and Moshref-Javadi, M. "Concurrent cell formation and layout design using scatter search", Int. J. Adv. Manuf. Tech., 71(1-4), pp. 1-22 (2014).
9. Saeidi, S., Solimanpur, M., Mahdavi, I. and Javadian, N. "A multi-objective genetic algorithm for solving cell formation problem using a fuzzy goal programming approach", Int. J. Adv. Manuf. Tech., 70(9-12), pp. 1635-1652 (2014).

10. Bootaki, B., Mahdavi, I. and Paydar, M.M. "A hybrid GA-AUGMECON method to solve a cubic cell formation problem considering different worker skills", Comput. Ind. Eng., 75, pp. 31-40 (2014).

11. Paydar, M.M. and Saidi-Mehrabad, M. "A hybrid genetic-variable neighborhood search algorithm for the cell formation problem based on grouping efficacy", Comput. Oper. Res., 40(4), pp. 980-990 (2013).

12. Solimanpur, M., Saeedi, S. and Mahdavi, I. "Solving cell formation problem in cellular manufacturing using ant-colony-based optimization", Int. J. Adv. Manuf. Tech., 50(9-12), pp. 1135-1144 (2010).

13. Lian, J., Liu, C., Li, W., Evans, S. and Yin, Y. "Formation of independent manufacturing cells with the consideration of multiple identical machines", Int. J. Prod. Res., 52(5), pp. 1363-1400 (2014).

14. Rezazadeh, H., Mahini, R. and Zarei, M. "Solving a dynamic virtual cell formation problem by linear programming embedded particle swarm optimization algorithm", Appl. Soft. Comput., 11(3), pp. 3160-3169 (2011).

15. Kashan, A.H., Karimi, B. and Noktehdan, A. "A novel discrete particle swarm optimization algorithm for the manufacturing cell formation problem", Int. J. Adv. Manuf. Tech., 73(9-12), pp. 1543-1556 (2014).

16. Saxena, L.K. and Jain, P.K. "Dynamic cellular manufacturing systems design: a comprehensive model", Int. J. Adv. Manuf. Tech., 53(1-4), pp. 11-34 (2011).

17. Bajestani, M.A., Rabbani, M., Rahimi-Vahed, A.R. and Khoshkhou, G.B. "A multi-objective scatter search for a dynamic cell formation problem", Comput. Oper. Res., 36(3), pp. 777-794 (2009).

18. Shiyas, C.R. and Madhusudanan Pillai, V. "Cellular manufacturing system design using grouping efficacybased genetic algorithm", Int. J. Prod. Res., 52(12), pp. 3504-3517 (2014). 
19. Wang, X., Tang, J. and Yung, K.L. "Optimization of the multi-objective dynamic cell formation problem using a scatter search approach", Int. J. Adv. Manuf. Tech., 44(3-4), pp. 318-329 (2009).

20. Norman, B.A., Tharmmaphornphilas, W., Needy, K.L., Bidanda, B. and Warner, R.C. "Worker assignment in cellular manufacturing considering technical and human skills", Int. J. Prod. Res., 40(6), pp. 14791492 (2002).

21. Ghotboddini, M.M., Rabbani, M. and Rahimian, H. "A comprehensive dynamic cell formation design: Benders' decomposition approach", Expert. Syst. Appl., 38(3), pp. 2478-2488 (2011).

22. Defersha, F.M. and Chen, M. "A linear programming embedded genetic algorithm for an integrated cell formation and lot sizing considering product quality", Eur. J. Oper. Res., 187(1), pp. 46-69 (2008).

23. Cao, D., Defersha, F.M. and Chen, M. "Grouping operations in cellular manufacturing considering alternative routings and the impact of run length on product quality", Int. J. Prod. Res., 47(4), pp. 9891013 (2009).

24. Egilmez, G., Süer, G.A. and Huang, J. "Stochastic cellular manufacturing system design subject to maximum acceptable risk level", Comput. Ind. Eng., 63(4), pp. 842-854 (2012).

25. Sudhakara Pandian, R. and Mahapatra, S.S. "Manufacturing cell formation with production data using neural networks", Comput. Ind. Eng., 56, pp. 13401347 (2009).

26. Chung, S., Wub, T. and Chang, C. "An efficient tabu search algorithm to the cell formation problem with alternative routings and machine reliability considerations", Comput. Ind. Eng., 60(1), pp. 7-15 (2011).

27. Arikan, F. and Güngör, Z. "Modeling of a manufacturing cell design problem with fuzzy multi-objective parametric programming", Math. Comput. Model., 50(3-4), pp. 407-420 (2009).

28. Ferioli, F., Schoots, K. and Zwaan, B.C.C. "Use and limitations of learning curves for energy technology policy: A component-learning hypothesis", Energy Policy, 37(7), pp. 2525-2535 (2009).

29. Morrison, J.B. "Putting the learning curve in context", J. Bus. Res., 61(11), pp. 1182-1190 (2008).

30. Mahdavi, I., Paydar, M.M., Solimanpur, M. and Heidarzade, A. "Genetic algorithm approach for solving a cell formation problem in cellular manufacturing", Expert. Syst. Appl., 36(3), pp. 6598-6604 (2009).

31. Essafi, I., Mati, Y. and Pérès, S.D. "A genetic local search algorithm for minimizing total weighted tardiness in the job-shop scheduling problem", Comput. Oper. Res., 35(8), pp. 2599-2616 (2008).

32. Ahmadizar, F. and Farahani, M.H. "A novel hybrid genetic algorithm for the open shop scheduling problem", Int. J. Adv. Manuf. Tech., 62(5-8), pp. 775-787 (2012).
33. Bashiri, M. and Farshbaf Geranmayeh, A. "Tuning the parameters of an artificial neural network using central composite design and genetic algorithm", Scientia Iranica, 18(6), pp. 1600-1608 (2011).

34. Heizer, J. and Render, B., Operations Management, Prentice-Hall (2001).

35. Li, D.C. and Hsu, P.H. "Solving a two-agent singlemachine scheduling problem considering learning effect", Comput. Oper. Res., 39(7), pp. 1644-1651 (2012).

36. Hosseini, N. and Tavakkoli-Moghaddam, R. "Two meta-heuristics for solving a new two machine flowshop scheduling problem with the learning effect and dynamic arrivals", Int. J. Adv. Manuf. Tech., 65(5-8), pp. 771-786 (2013).

\section{Biographies}

Masoud Rabbani is a Professor at School of Industrial Engineering and Chairman of the Energy Management and Planning Research Institute at the University of Tehran, Iran. He received his $\mathrm{PhD}$ in Industrial Engineering at Amirkabir University of Technology, Iran. His research interests include Manufacturing and Production Systems, Soft Computing Techniques, Multi-Criteria Decision Making (MCDM), Transportation and Scheduling. He has published many national and international journals.

Hamed Habibnejad-Ledari is an MSc Candidate at School of Industrial Engineering at the University of Tehran. He obtained his BSc in Industrial Engineering from the Babol University of Technology in 2013. His fields of interest include operation research, production planning and control, healthcare engineering, and heuristic algorithms.

Hamed Rafiei obtained his $\mathrm{PhD}$ certificate from School of Industrial \& Systems Engineering, College of Engineering, University of Tehran. He received his $\mathrm{BSc}$ and MSc degrees in Industrial Engineering from University of Tehran as an honor. His research interests include production planning and control, pricing, and applications of operations research in operations management on which he has published several papers in international journals and conference proceedings.

Amir Farshbaf-Geranmayeh is a $\mathrm{PhD}$ candidate at school of Industrial Engineering. He received his MS and BS degrees in Industrial Engineering at Shahed University and Tabriz University in 2009, respectively. His research interests are revenue management, healthcare engineering, supply chain management, multiple response optimization, and artificial intelligent and its applications in industrial engineering. 